\title{
Research on Human Resource Planning and Management of SMEs
}

\author{
Yanna Wei \\ Xi'an International University, Xi'an, Shaanxi, 710077
}

Keywords: SMEs, human resource, planning and management

\begin{abstract}
The current dilemma of human resources planning in SMEs is mainly manifested in the lack of different types of human resource planning, the lack of scientific guidance for human resource planning, the imperfect support system for human resources planning, and the ineffective implementation of human resources planning. The reasons for exploring the dilemma of SMEs' human resources planning are mainly the vague development strategy of SMEs, the incomplete understanding of human resources planning, the shortage of human resources management and the shortage of specialized high-quality human resources managers, and the relatively low quality of employees. The strategy to eliminate the dilemma of SME human resource planning should focus on internal development and external experience.
\end{abstract}

\section{Introduction}

As the most dynamic market entity, SMEs have made important contributions to the development of China's economy and society in the development of regional economy, job creation, consumer demand and management system innovation. Human resource planning refers to the enterprise's strategic process and development goals, based on changes in its internal and external environment, predicting the future development of the company's human resources needs, and the human resources activities to meet this need. Human resource planning is the foundation of enterprise human resource management. It consists of overall planning and various business plans, providing reliable information and basis for management activities, and thus ensuring the orderly management activities. However, in the process of human resources management of SMEs, managers generally have many confusions and helplessness in the formulation and implementation of human resource planning, which makes human resources planning face dilemma and crisis of dispensability and poor implementation. Improper human resource planning has led to problems such as unclear job responsibilities in SMEs, unreasonable staffing, unbalanced employee quality structure, and lack of development motivation, thus hampering the development speed of enterprises and missing opportunities for development.

\section{Performance of Dilemma in SMEs' Human Resources Planning}

In the practice of human resource management, SMEs lacking in human resource planning mainly include three types. First, the small and medium-sized enterprises in the early stage of establishment, the scale of business and personnel is relatively small, and the division of labor within the enterprise is not clear. The enterprise considers more about how to survive rather than how to develop. The formulation of human resources planning has no meaning for enterprises. . Second, enterprises with human resources management in a heterogeneous and disorderly management stage. Many practical tasks of human resource planning are ongoing, but not systematic, such as: recruitment planning and training planning, etc. In progress, but not unified in a planning framework, so that the joint forces can not be formed between the various modules, ultimately leading to an increase in human labor costs, human resources can not serve the realization of strategic goals. The third is family-owned or traditional SMEs. The competition of enterprises and the competition for talents are not very fierce. The requirements for human resources management of enterprises only remain within the relevant interest groups, so human resources planning is lacking. 
The lack of scientific guidance in the formulation of human resources planning, the deviation of technology application in human resource planning, makes the human resources planning of SMEs out of the actual situation of enterprises. In the field of human resource management research, the existing human resource management theory basically comes from the empirical research on large enterprises with relatively standardized management. For the applicability of these theories in the process of human resources management of SMEs, American scholars (2002) After conducting research, they concluded that the existing human resource management theory is rarely suitable for SMEs. However, due to the small scale of the enterprise and the irregular organization, the human resource management of SMEs has rarely received the attention of researchers for a long time. . The same is true for human resources planning. In the research and operation of many human resources planning, it is mainly aimed at large enterprises or groups with large scale, sound organizational structure and perfect human resources functions. The research results and methodologies for human resources planning of small and medium-sized enterprises are few. This has resulted in the lack of scientific guidance and reference in the process of human resources planning for SMEs, which makes the application of human resources planning easy to bias. Mainly reflected in the following aspects: First, disregarding the actual situation of the enterprise, copying the human resources planning methods and technologies of large enterprises, resulting in a lack of applicable environment for SME human resources planning, from reality, short life, or even impossible to implement. Secondly, blindly carrying out human resource planning, not knowing the development strategy of the enterprise, not understanding the supply and demand situation of human resources inside and outside the enterprise, lacking the guidance of the basic human resources planning techniques and methods, and ultimately leading to the operability of the entire human resources planning. . The human resources planning of small and medium-sized enterprises cannot copy the dogma of large enterprise planning, but should solve the problem based on it and form a flexible and changeable planning mode with its own style and characteristics.

\section{The Causes of Dilemma in SMEs' Human Resources Planning}

There are many reasons for the dilemma of SME human resource planning. There are both external reasons and internal reasons, but the fundamental reason lies within the enterprise. From the internal reasons of China's small and medium-sized enterprises, it is mainly reflected in the variability and ambiguity of the development strategy of SMEs; the understanding of human resources planning is not comprehensive; the human resource management model unique to SMEs has defects; the high-quality human resources management of SMEs There is a shortage of people, and the quality of employees is relatively low. In the human resources development and management activities, we should start with strategic goals and take strategy as a guide to ensure the correctness and effectiveness of human resources policies. Therefore, the premise of human resource planning is that enterprise development and corporate strategy must be clarified first, and then can be decomposed into human resources. Then there will be personnel demand planning, recruitment planning, salary and welfare plans and so on. SMEs generally lack a clear development strategy, especially in the rapid expansion stage, often involved in different business areas, many of which are emerging industries. These emerging industries have no mature experience in $R \& D$, marketing, management, and service. In particular, some newly developed projects are not as mature as traditional businesses. Therefore, it is impossible to have a clear plan for human resources management. It can only be one step and one step. The shortcomings of China's SMEs in the human resources management system are the main factors that cause the crisis of human resources planning in SMEs. At present, the defects of human resources management in China's SMEs mainly exist in the following aspects: First, because the scale of enterprises is medium to small, the division of enterprise functional departments is relatively rough, and some enterprises do not even have independent human resources management departments to perform the functions of human resources management. Although some enterprises have independent personnel departments, they often have a small division of labor and a small number of people. Second, the human resource management system of the enterprise may be sound, but the individual will of the leader is often 
above the system, making the system ineffective. Third, SMEs generally have short-sightedness in the use of human resources in human resource management, that is, they only emphasize the use and management of human resources, and do not pay attention to the training, development and incentives of human resources. Under this kind of human resource management, employees are passive, restricting their full strengths and potentials and the further development of their careers. Therefore, the turnover rate of SME employees is relatively high. In the case of shortcomings in the human resources management system of SMEs, human resources planning is inevitably lacking, planning is not comprehensive, and it is impossible to implement.

\section{Suggested Countermeasures for Problems in SMEs' Human Resources Planning}

Human resource planning is the guarantee for the sustainable development of the organization, and its importance is especially prominent for small and medium-sized enterprises seeking to grow and develop. However, scientifically formulating and effectively implementing human resource planning does not depend on the size of the company. The most important thing is whether it can formulate appropriate strategies based on the company's development strategy and management characteristics. In view of the appearance and causes of the crisis of human resources planning in SMEs, the author believes that the countermeasures to improve the planning crisis should mainly include the following aspects:

The main measures to solve the current lack of China's small and medium-sized human resource planning and the actual development of the enterprise are to clarify the development strategy of the enterprise, strengthen the scientific understanding of the human resources planning, and promote the integration of human resource planning and corporate strategy. Clarify the corporate development strategy to determine the staged strategy for development based on the life cycle of SMEs and actual business conditions. If the long-term strategy is difficult to determine due to changes in the external environment of the market, the direction of short-term or annual corporate development should also be determined. Specifically, we must first improve the strategic position of human resources planning, and the enterprise management decision-making layer should attach great importance to it and incorporate it into the overall development strategy of the enterprise; secondly, strengthen the content, methods and technologies of human resource planning and the planning of SMEs. The development of special aspects and other aspects of training to ensure that the development and implementation of human resources planning is in line with the actual development of the enterprise. The integration of human resource planning and enterprise development strategy is the highest level of human resources planning development of SMEs. The implementation of human resources planning ultimately promotes the development and growth of SMEs, and avoids the breeding and spread of various human resources losses within the enterprise.

Continue to promote the transformation of human resources management and improve the human resources management system, mainly to eliminate the shortcomings of human resources management of SMEs, and create a good operating environment for the formulation and implementation of human resources planning. Only by implementing effective reforms can we build a well-functioning support platform for SME human resource planning. The perfect human resources planning support platform, in addition to the job analysis, job setting, performance management, incentive mechanism, career planning, etc. inherent in its functional departments, some even exceed the field of human resource management, such as the planning and budget management system, Enterprise target management system, etc. Strengthening the cultivation of human resources management teams in SMEs is also an important way to improve the crisis of human resources planning. Due to the strong competition of the external environment faced by enterprises, the formulation of human resources planning is more complicated. Therefore, the developers of SME human resource planning should have high strategic thinking and good practical experience. Therefore, strengthening the cultivation of high-level and high-quality human resources management teams for SMEs and improving their overall professional quality have become the key to the success of human resources planning. In addition, improving the current low-level status of SME staff can also greatly promote the concept recognition and implementation of human resources 
planning activities.

\section{Conclusion}

Managers must correctly identify the appearance of human resources planning crisis in SMEs, thoroughly analyze their internal causes, and on this basis, scientifically formulate and effectively implement targeted countermeasures. In this way, the human resources planning of SMEs can get rid of the dilemma of strategic separation and separation from reality. The effective planning activities will promote the progress of human resource management and development. The benign operation of these human resources will help China's SMEs to break through the development bottleneck and welcome a new round of leap-forward development.

\section{References}

[1] Du Yang, Xu Pengfei. How to carry out effective human resource management for small and medium-sized enterprises [J]. Electromechanical Information, 2009 (4).

[2] Tong Yanan, Wang Qi. Misunderstandings and strategies for SME management [J]. Market Weekly, 2009 (8).

[3] An Hongzhang. On the main factors affecting the human resources strategy of enterprises [J]. Economics and Management Research, 2002, (4): 37- 39.

[4] Xu Bin. Strategic Choice of Human Resource Management Talent Strategy of Foreign Enterprises and Domestic Enterprises [J]. Population and Economy, 2000, (4): 50- 54. 